\title{
Downregulation of CD147 induces malignant melanoma cell apoptosis via the regulation of IGFBP2 expression
}

\author{
SHUANG ZHAO ${ }^{1,2^{*}}$, LISHA WU ${ }^{3 *}$, YEHONG KUANG ${ }^{1,2^{*}}$, JUAN SU ${ }^{1,2}$, ZHONGLING LUO $^{1,2}$, YAN WANG ${ }^{4}$ \\ JINMAO LI ${ }^{1}$, JIANGLIN ZHANG ${ }^{1,2}$, WANGQING CHEN ${ }^{1,2}$, FANGFANG LI ${ }^{1,2}$, YIJING HE ${ }^{1,2}$, \\ JUAN TAO $^{5}$, JIANDAZHOU ${ }^{6}$, XIAOWEI XU ${ }^{7}, \mathrm{CONG} \mathrm{PENG}^{1,2}$ and XIANG CHEN ${ }^{1,2}$ \\ ${ }^{1}$ Department of Dermatology, Xiangya Hospital; ${ }^{2}$ Hunan Key Laboratory of Skin Cancer and Psoriasis, \\ Xiangya Hospital; ${ }^{3}$ Institute of Medical Sciences, Xiangya Hospital, Central South University, Changsha, \\ Hunan 410008; ${ }^{4}$ Institute of Dermatology, Chinese Academy of Medical Sciences and \\ Peking Union Medical College, Nanjing, Jiangsu 210042; ${ }^{5}$ Department of Dermatology, \\ Affiliated Union Hospital, Tongji Medical College, Huazhong University of Science and Technology, \\ Wuhan, Hubei 430030; ${ }^{6}$ Department of Plastic Surgery of The Third Xiangya Hospital, \\ Central South University, Changsha, Hunan 410013, P.R. China; ${ }^{7}$ Department of Dermatology, \\ University of Pennsylvania School of Medicine, Philadelphia, PA 19104, USA
}

Received May 2, 2018; Accepted September 7, 2018

DOI: 10.3892/ijo.2018.4579

\begin{abstract}
Cluster of differentiation (CD)147, as a transmembrane glycoprotein, is highly expressed in a variety of tumors. Accumulating evidence has demonstrated that CD147 serves critical roles in tumor cell death and survival; however, the underlying mechanism requires further investigation. In the present study, it was revealed that CD147 knockdown significantly increased melanoma cell apoptosis. In addition, downregulation of CD147 reversed the malignant phenotype of melanoma, as demonstrated by the induction of tumor cell apoptosis in a xenograft mouse model. In addition, a human apoptosis antibody array was performed and 9 differentially expressed apoptosis-related proteins associated with CD147 were identified, including insulin-like growth factor-binding protein 2 (IGFBP2). Additionally, CD147 knockdown was observed to significantly decreased IGFBP2 expression at the mRNA and protein levels in melanoma cells. Providing that IGFBP2 is a downstream molecule in the phosphatase and tensin homolog (PTEN)/phosphoinositide 3-kinase $(\mathrm{PI} 3 \mathrm{~K}) /$ protein kinase B (AKT) signaling pathway, the effects
\end{abstract}

Correspondence to: Professor Xiang Chen or Professor Cong Peng, Department of Dermatology, Xiangya Hospital, Central South University, 87 Xiangya Road, Changsha, Hunan 410008, P.R. China E-mail: chenxiangck@126.com

E-mail: pengchongpeng@hotmail.com

*Contributed equally

Key words: melanoma, cluster of differentiation 147, insulin-like growth factor-binding protein 2, apoptosis, phosphatase and tensin homolog/phosphoinositide 3-kinase/protein kinase B of CD147 on this particular pathway were investigated. Interestingly, the expression of phosphorylated (p)-AKT and p-mechanistic target of rapamycin was attenuated, whereas PTEN was markedly upregulated in CD147-underexpressing melanoma cells. Furthermore, application of a PI3K-specific inhibitor also decreased IGFBP2 expression. Importantly, IGFBP2 was highly expressed in clinical tissues of melanoma compared with the control group, and its expression exhibited a positive association with CD147. The present study revealed that CD147 served a critical role in mediating the apoptosis of melanoma cells via IGFBP2 and the PTEN/PI3K/AKT signaling pathway. IGFBP2 and CD147 were observed to be overexpressed in clinical melanoma tissues; IGFBP2 was shown to be positively associated with CD147 expression, suggesting that CD147 may be considered as a potential therapeutic target for chemotherapy or prevention for in melanoma.

\section{Introduction}

Malignant melanoma (MM) is one of the most aggressive types of malignant tumor, and is responsible for the majority of skin cancer-associated mortalities $(1,2)$. Extracellular matrix metalloproteinase inducer, also known as Basigin and cluster of differentiation 147 (CD147), is a highly glycosylated type-I transmembrane protein of the immunoglobulin superfamily (3). A previous study revealed that CD147 served a key role in cellular apoptosis. Inhibition of CD147 expression by short hairpin (sh)RNA increased the chemosensitivity of oral squamous cell carcinoma cells, specifically a multidrugresistant cell line, by downregulating the expression of the anti-apoptotic gene X-linked inhibitor of apoptosis (4). Recently, propranolol was reported to induce the apoptosis of vascular endothelial cells by decreasing the expression levels of CD147 in the treatment of infantile hemangiomas (5). Overexpression of CD147 also facilitates the induction of 
apoptosis of Jurkat $\mathrm{T}$ and Chinese hamster ovary cells via methotrexate treatment (6); however, the mechanism underlying the effects of CD147 on apoptosis in melanoma cells remains unclear.

The phosphatase and tensin homolog (PTEN)/phosphoinositide 3 -kinase (PI3K)/protein kinase B (AKT) signaling pathway is a pivotal pathway in melanomagenesis, and is involved in a variety of biological processes, including cell death and survival, cell proliferation, angiogenesis and autophagy $(7,8)$. Under physiological conditions, the activation of PI3K facilitates transfer of a phosphoryl group to form phosphatidylinositol $(3,4,5)$-trisphosphate (PIP3); PTEN, characterized by phosphatase activity, negatively regulates this procedure (9). PIP3 acts as a secondary messenger to activate the downstream signaling pathway; as a consequence, AKT and its substrate mechanistic target of rapamycin (mTOR), are activated and are able to induce the synthesis of proteins involved in cell survival, proliferation and apoptosis (10). In melanoma, the PTEN gene has been observed to possess deletions in $\sim 30 \%$ of sporadic cases (with loss of the corresponding protein in $5-20 \%$ of primary melanomas) and in $\sim 40 \%$ of melanoma cell lines $(11,12)$. Therefore, PTEN is a key molecule associated with the pathogenesis of melanoma.

Insulin-like growth factor-binding protein 2 (IGFBP2) belongs to the IGF-binding protein family, containing six members (IGFBP1-6) with a high affinity of IGF1 and IGF2. Previous studies $(13,14)$ have revealed that IGFBP2 could associate with IGFs to inhibit binding to the receptor, thereby attenuating IGF-induced tumorigenesis; however, accumulating evidence has demonstrated that IGFBP2 exhibits oncogenic effects, including the suppression of apoptosis, and facilitating cell growth and migration (15), which are independent of the ability of IGFBP2 to associate with IGFs.

The aim of the present study was to investigate the role of CD147 in melanoma cell apoptosis by examining the effects of CD147 knockdown on IGFBP2 expression in melanoma cells and the activity of the AKT/mTOR signaling pathway to determine whether the CD147/IGFBP2 axis serves a key role in melanoma cell apoptosis. In addition, the present study investigated the underlying mechanism.

\section{Materials and methods}

Cell culture and lentiviral infection. The MM cell lines, A375 and SK-MEL-28, (American Type Culture Collection, Manassas VA, USA) were stored in our laboratory (Hunan Key Laboratory of Skin Cancer and Psoriasis, Xiangya Hospital, Central South University, Changsha, China), and cultured in high-glucose Dulbecco's modified Eagles medium (DMEM) supplemented with $10 \%$ fetal bovine serum (FBS; Gibco; hermo Fisher Scientific, Inc., Waltham, MA, USA) and antibiotics (1\% penicillin-streptomycin). The cells were maintained at $37^{\circ} \mathrm{C}$ in an incubator under $5 \% \mathrm{CO}_{2}$.

For lentiviral packaging as previously established (16), briefly, 293T cells were stored in our laboratory, and transfected with vectors containing an shRNA targeting CD147 (shRNA-CD147-C1, forward sequence 5'-GATCCCCGTCGT CAGAACACATCAACTTCAAGAGAGTTGATGTGTTCTG ACGACTTTTTGGAAA-3', reverse sequence: 5'-AGCTTTT CCAAAAAGTCGTCAGAACACATCAACTCTCTTGAAG
TTGATGTGTTCTGACGACGGG-3' or shRNA-CD147-C2, forward sequence: 5'-GATCCCCTGACAAAGGCAAGAAC GTCTTCAAGAGAGACGTTCTTGCCTTTGTCATTTTTG GAAA-3', reverse sequence: 5'-AGCTTTTCCAAAAATGAC AAAGG CAAGAACGTCTCTCTTGAAGACG TTCTTGCC TTTGTCAGGG-3', AgeI and EcoRI restriction sites) or a negative control (pLKO.1-sh-Mock, sequence: 5'-AGAAGT GTAGCATGCAGATTACT ATTG AGCCTTATCGGAC TTGACGTCAGTA GTCAACACTCTC-3'), and packaging vectors (psPAX2 and pMD2-G) using TurboFest transfection reagent (Thermo Fisher Scientific, Inc.) for $24 \mathrm{~h}$. Then, the supernatant fraction containing lentiviral particles was collected at 48 and 72 h, respectively; transduction with A375 and SK-MEL-28 cells was conducted using $10 \mu \mathrm{g} / \mathrm{ml}$ Polybrene (Sigma-Aldrich; Merck KGaA, Darmstadt, Germany, cat. no. H9268) and $1 \mathrm{ml}$ lentiviral fraction in 6-well plate. Each cell line was infected for three wells. The medium (10\% FBS DMEM) was replaced with fresh medium containing $1 \mu \mathrm{g} / \mathrm{ml}$ puromycin for stable cell selection following $16 \mathrm{~h}$ post-transfection. In the current study, pLKO.1-sh-CD147-C2 vector was used for subsequent analysis.

LY294002, a PI3K signaling pathway inhibitor, was purchased from Sigma-Aldrich (Merck KGaA), dissolved in DMSO and diluted to a final concentration of $50 \mu \mathrm{g} / \mathrm{ml}$; LY294002 was applied to cells at room temperature for $24 \mathrm{~h}$; $0 \mu \mathrm{g} / \mathrm{ml} \mathrm{LY} 294002$ was used as the control.

Flow cytometry and transmission electron microscopy. Cellular apoptosis was determined by flow cytometry, according to the manufacturer's protocols of an Annexin V-fluorescein isothiocyanate (FITC) apoptosis detection kit (C1062, (Beyotime Institute of Biotechnology, Beijing, China). Briefly, a total of $5 \times 10^{5}$ cells were harvested and collected, resuspended in $195 \mu \mathrm{l}$ binding buffer (included in kit), and stained with $5 \mu \mathrm{l}$ Annexin V-fluorescein isothiocyanate conjugate and $10 \mu \mathrm{l}$ propidium iodide solution at room temperature for $20 \mathrm{~min}$. The stained cells were then analyzed using a FACSCanto II flow cytometer using BD FACSDiva ${ }^{\mathrm{TM}}$ software v 6.0 (BD Biosciences, San Jose, CA, USA).

Transmission electron microscopy was performed according to previous our study (4), briefly, cells were first fixed with $2 \%$ paraformaldehyde and $2 \%$ glutaraldehyde, and then with $2 \%$ osmium tetroxide for $\leq 2 \mathrm{~h}$. Fixed specimens were dehydrated, embedded and sliced with an ultra-microslicing microtome (LKB-III, LKB Instruments, Victoria, Australia). Samples were then examined by transmission electron microscopy (H-7500, magnification, x5,000, Hitachi, Ltd., Tokyo, Japan).

Human apoptosis assay. Detection of apoptotic proteins was performed using the RayBio ${ }^{\circledR}$ human apoptosis array G1 kit (cat. no. AAH-APO-G1; RayBioTech, Inc., Guangzhou, China). The assay conducted in the present study detects 43 different apoptotic proteins, as well as GAPDH as a loading control. The assays for A375-sh-Mock and A375-sh-CD147 were performed using 6-well glass slides, according to the manufacturer's protocols. SK-MEL-28 cells were used as confirmation. Then, the assay slides were analyzed by Genomax Technologies (Singapore) using a microarray scanner (G2505C, Agilent Technologies Inc., Santa Clara, CA, USA). Data obtained from 
scanning were exported for analysis using Agilent feature extraction software version 10.5 (Agilent Technologies Inc). and the relative fold changes in the expression profile of each protein were calculated; two independent experiments $(n=4)$ were performed to confirm the results.

Reverse transcription-quantitative polymerase chain reaction (RT-qPCR) and western blotting. For qPCR, total cellular RNA was extracted using TRizol reagent (Thermo Fisher Scientific, Inc.). A total of $3 \mu \mathrm{g}$ RNA was used as a template for RT (cat. no. R233-01, Vazyme, Piscataway, NJ, USA), the procedure of RT comprised two steps, the first at $42^{\circ} \mathrm{C}$ for $2 \mathrm{~min}$, then at $50^{\circ} \mathrm{C} 15 \mathrm{~min}$, followed by the second step, final at $85^{\circ} \mathrm{C}$ for $5 \mathrm{sec}$ to terminate the reaction. $\mathrm{qPCR}$ was performed using the ABI 7500 system (Applied Biosystems; Thermo Fisher Scientific, Inc.). Each $20-\mu 1$ PCR reaction mixture contained $1 \mu \mathrm{l}$ cDNA product, $2 \mu \mathrm{l}$ specific forward/universal primer mix, and $10 \mu \mathrm{l}$ SYBRGreen $2 \mathrm{X}$ Universal PCR Master Mix (cat. no. Q141-02, Vazyme). The thermocycling conditions of qPCR were: Denaturation at $95^{\circ} \mathrm{C}$ for $5 \mathrm{~min}$, then extension at $60^{\circ} \mathrm{C}$ for 40 cycles. The IGFBP 2 primers used were as 5'-AGAAGGTCACTGAGCAGCAC-3' (forward), and 5'-GAGGTTGTACAGGCCATGCT-3' (reverse). $\beta$-actin (forward, 5'-GTCATCACCATTGGCAATGAG-3' and reverse, 5'-CGTCACACTTCATGATGGAGTT-3') were determined as a control by using the $2^{-\Delta \Delta \mathrm{Cq}}$ analysis method (17). Triplicate determination was repeated 3 times.

For western blotting, cells were harvested and lysed with radioimmunoprecipitation assay lysis buffer (Santa Cruz Biotechnology, Inc., Dallas, TX, USA). Total proteins were quantified via a Bradford protein assay (Beyotime Institute of Biotechnology). The protein samples (30 $\mu \mathrm{g} / \mathrm{sample})$ were separated by $10 \%$ SDS-PAGE and transferred onto a polyvinylidene difluoride membrane. The membranes were incubated with primary antibodies at $4^{\circ} \mathrm{C}$ in $5 \%$ non-fat dried milk in TBS buffer for overnight. The membranes were washed three times with TBS buffer and incubated with horseradish peroxidase secondary antibodies (cat. nos. AS003 and AS014, 1:5,000) from ABclonal Biotech Co., Ltd. (Wuhan, China) at room temperature for $1 \mathrm{~h}$. The blots were detected using enhanced chemiluminescent reagents Clarity $\mathrm{Max}^{\mathrm{TM}}$ Western ECL Blotting Substrates (cat. no. 1705062) (Bio-Rad Laboratories, Inc., Hercules, CA, USA) according to the manufacturer's protocols. The following primary antibodies were used: Anti-CD147 (cat. no. sc-21746, 1:1,000; Santa Cruz Biotechnology, Inc.), and anti-IGFBP2 (cat. no. ab109284, 1:1,000; Abcam), anti-PTEN (cat. no. ab32199, 1:1,000; Abcam), phosphorylated (p)-AKT (cat. no. 9271, 1:1,000), AKT (cat. no. 9272, 1:1,000), p-mTOR (cat. no. 2971, 1:1,000) and mTOR (cat. no. 2972, 1:1,000) and cle-PARP (cat. no. 9532S, 1:1,000) were purchased from Cell Signaling Technology, Inc., Danvers, MA, USA). $\beta$-actin (cat. no. sc-517582, 1:1,000; Santa Cruz Biotechnology, Inc.) or GAPDH (sc-47724, 1:1,000; Santa Cruz Biotechnology, Inc.) was used as an internal reference. The band intensity was quantified by using Bio-Rad Image $\mathrm{Lab}^{\mathrm{TM}}$ software version 6.1 (Bio-Rad Laboratories, Inc.).

Tumor xenograft mice. Tumor xenograft mouse models were previously established by our laboratory (18) and the animal study was approved by the Ethics Committee of Xiangya
Hospital, Central South University (Changsha, China). All animal experiments were conducted in accordance with the Guidelines of The National Institutes of Health Guide for the Care and Use of Laboratory Animals (19). Briefly, A375 cells stably transduced with sh-CD147 or sh-Mock lentiviruses, were harvested, washed with 1X PBS buffer, re-suspended in cold serum-free high-glucose DMEM, and then subcutaneously injected $\left(5 \times 10^{6} / 0.15 \mathrm{ml}\right.$ cells) into the right flank of 4-6-week-old male BALB/c nude mice (Shanghai SLAC Laboratory Animal Co., Ltd., Shanghai, China) and 5 mice for each group. All mice were exposed to a $12 \mathrm{~h}$ light/dark cycle, supplied with free food and drinking water under specificpathogen free condition. The tumors were measured using calipers and the tumor volumes were calculated using the following formula: Length $\mathrm{x}$ width $\mathrm{x}$ height $\mathrm{x} 0.52$. The animals were sacrificed 35 days following tumor cell inoculation, and the tumor tissues were collected and fixed in $10 \%$ buffered formalin, embedded in paraffin, sectioned at $5 \mu \mathrm{m}$ and stained with H\&E based on our previous study (18), or subjected to immunohistochemical analysis.

Immunohistochemical analysis. Tumor tissues were obtained from A375-sh-CD147 and A375-sh-Mock nude mouse xenografts. A human melanoma tissue array was purchased from Alenabio (Xi'an, China), including 128 primary melanomas and 64 metastatic melanomas (cat. nos. M1004 and M1004a). In addition, we also collected 15 paraffin-embedded specimens with a clinical diagnosis of nevus from the Department of Dermatology, Xiangya Hospital (Changsha, China) from 2015 to 2017 , the average age was $35.13 \pm 12.61$ years-old, and the sex ratio was 1.14 ( 8 male):1 ( 7 female). Immunohistochemical staining was performed using a biotin-streptavidin horseradish peroxidase detection kit (OriGene Technologies, Inc., Beijing, China), according to the manufacturer's protocols. Briefly, the slides were heated at $60^{\circ} \mathrm{C}$ for $2 \mathrm{~h}$, dewaxed in turpentine and rehydrated in a graded ethanol series and washed with $1 \mathrm{X}$ PBS. Following antigen retrieval, and inactivation of endogenous peroxidase activity with $3 \% \mathrm{H}_{2} \mathrm{O}_{2}$, the slides were incubated with CD147 (1:100) or IGFBP2 antibodies (1:100) at $4^{\circ} \mathrm{C}$ in a humidified chamber overnight. The secondary antibody conjugated with biotin from the detection kit (OriGene Technologies, Inc.) was applied for $1 \mathrm{~h}$ at room temperature. Horseradish peroxidase-streptavidin (OriGene Technologies, Inc.) was added to the slides for $30 \mathrm{~min}$, then the slides were developed in 3,3-diaminobenzidine (DAB) and counterstained with hematoxylin, and mounted in neutral balsam. For semiquantitative analysis, the positive areas (\%) in each image were quantified using Image-Pro Plus 6.0 software (Media Cybernetics, Inc., Rockville, MD, USA). The cut-off values of expression for partial staining in $<10 \%$ tumor cells was considered as weak, staining in $10-40 \%$ tumor cells was considered moderate, and staining in $>40 \%$ tumor cells as strong expression.

A terminal deoxynucleotidyl-transferase-mediated dUTP nick end labeling (TUNEL) assay of the tumor tissues was performed using a TUNEL system (Promega Corporation, Madison, WI, USA), according to the manufacturer's protocols. Briefly, the slides were fixed in $4 \%$ formaldehyde in PBS for $15 \mathrm{~min}$ at room temperature, the procedure of permeabilization and equilibration was performed, and $\mathrm{TdT}$ reaction 
A

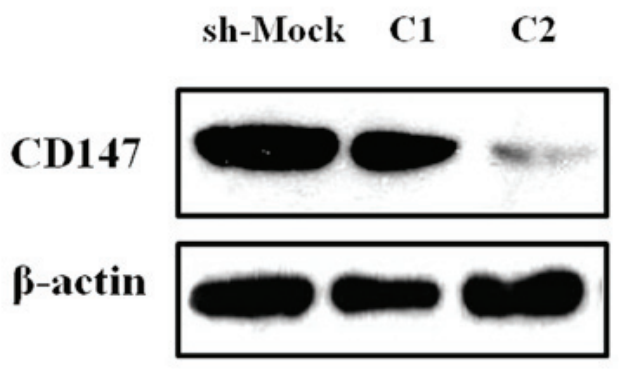

B
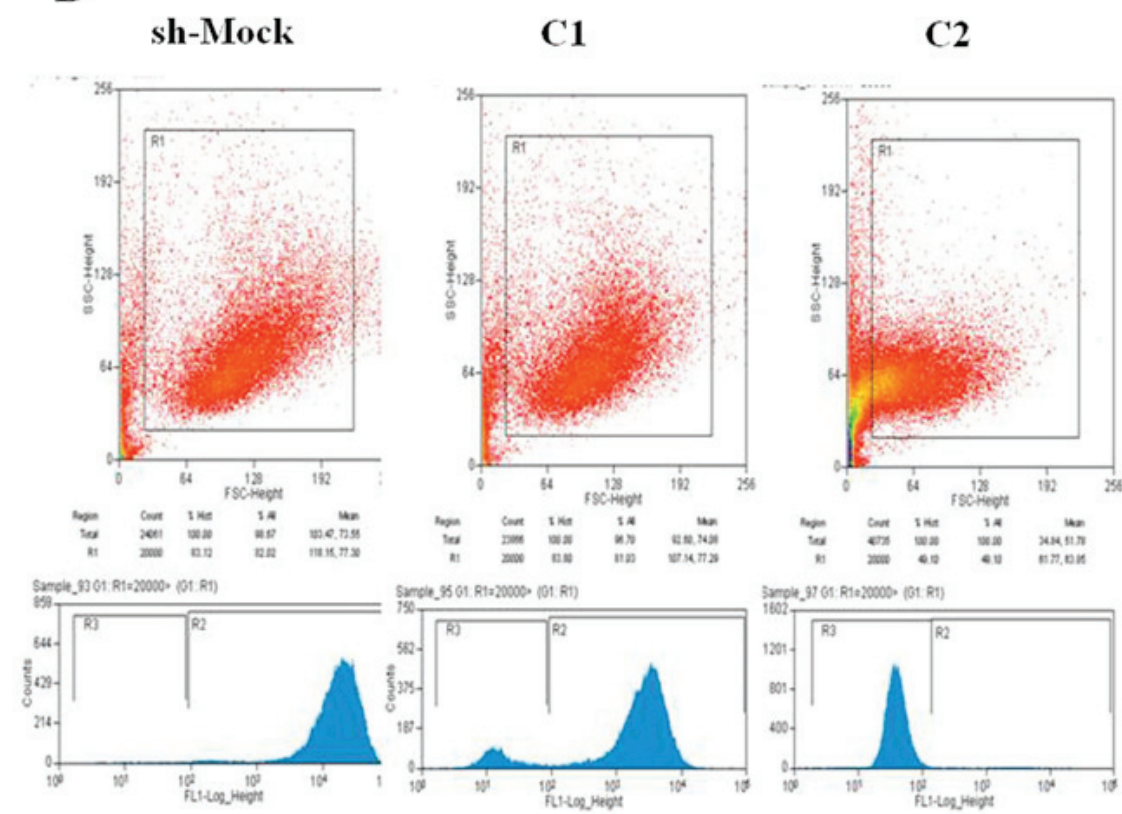

Figure 1. Induction of downregulated CD147 expression in melanoma A375 cells. (A) Transfection efficiency of pLK0.1-sh-CD147 (C1 or C2) and the control sh-Mock vectors in melanoma A375 cells was determined via western blotting to confirm CD147 protein expression. Transfection with the sh-CD147-C2 vector notably inhibited CD147 protein expression in A375 cells. (B) Stable downregulation of CD147 in A375 sh-CD147-C1 and -C2, and the control sh-Mock-transfected cells was assessed via flow cytometry analysis. Transfection with pLK0.1-sh-Mock vector into A375 is referred to as Sh-Mock. C1 or C2, transfection with pLK0.1-sh-CD147 vector; CD147, cluster of differentiation 147; sh, short hairpin RNA.

mix was added to the slides and incubated for $60 \mathrm{~min}$ at $37^{\circ} \mathrm{C}$ in a humidified chamber. The slides were washed with PBS, then DAB staining at room temperature and developed until there is a light brown background under microscope detection, then mounting were conducted. Semi-quantitation of TUNEL-positive cells was performed using Image-Pro Plus 6.0 software.

Statistical analysis. All data are presented as the mean \pm standard deviation from independent samples analyzed in three replicates. SPSS version 18.0 (SPSS, Inc., Chicago, IL, USA) was used for analysis. A Student's t-test or one-way analysis of variance was used to determine statistical differences. $\mathrm{P}<0.05$ was considered to indicate a statistically significant difference.

\section{Results}

Inhibition of CD147 promotes apoptosis in melanoma cell lines. In the present study, two stable melanoma cell lines with CD147 downregulation (referred to as C1 and C2) were generated. The protein expression levels of CD147 were notably decreased in sh-CD147-C2-transfected A375 cells compared with the sh-Mock-transfected cells (Fig. 1A). In addition, the results of the flow cytometry also suggested that CD147 expression was markedly inhibited in melanoma A375 cells, particularly within sh-CD147-C2-transfected cells (Fig. 1B).

In addition, the rate of apoptosis was determined by flow cytometry. The results demonstrated that the apoptotic rate of A375-sh-CD147 cells was 22.24 $44.07 \%$, which was significantly higher compared with that of the control group $(5.08 \pm 1.28 \%, \mathrm{P}<0.01$; Fig. $2 \mathrm{~A}$ and B). Furthermore, the expression of the apoptosis-associated protein, cleaved poly (ADP-ribose) polymerase (cle-PARP), was also significantly increased in A375-sh-CD147 and SK-MEL-28-sh-CD147 cells compared with the control cells $(\mathrm{P}<0.01$; Fig. $2 \mathrm{C}$ and $\mathrm{D})$.

The morphology of A375 cells was evaluated by transmission electron microscopy. As presented in Fig. 2E, compared with sh-Mock-transfected cells, A375-sh-CD147 cells were small and round. The membranes were bulging and ballooning. Typical apoptotic morphological characteristics, including condensation and fragmentation of the nuclei, as well as blebbing of the membrane, were also observed. Collectively, these findings demonstrated that knockdown of CD147 expression significantly induced apoptosis in melanoma cell lines. 
A

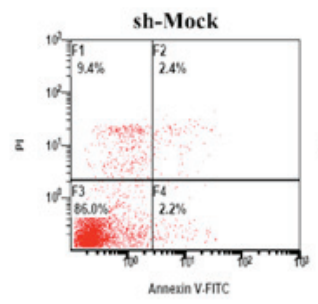

C

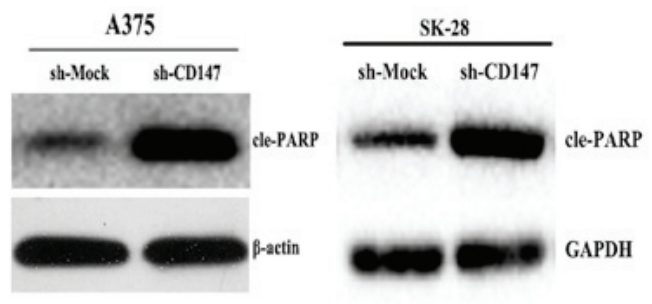

E

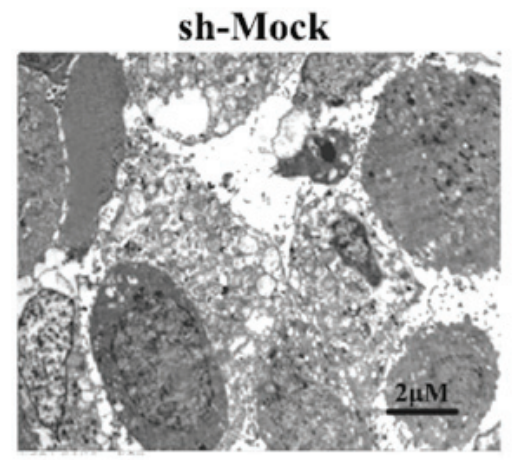

B

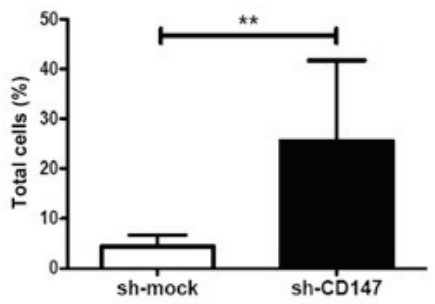

D
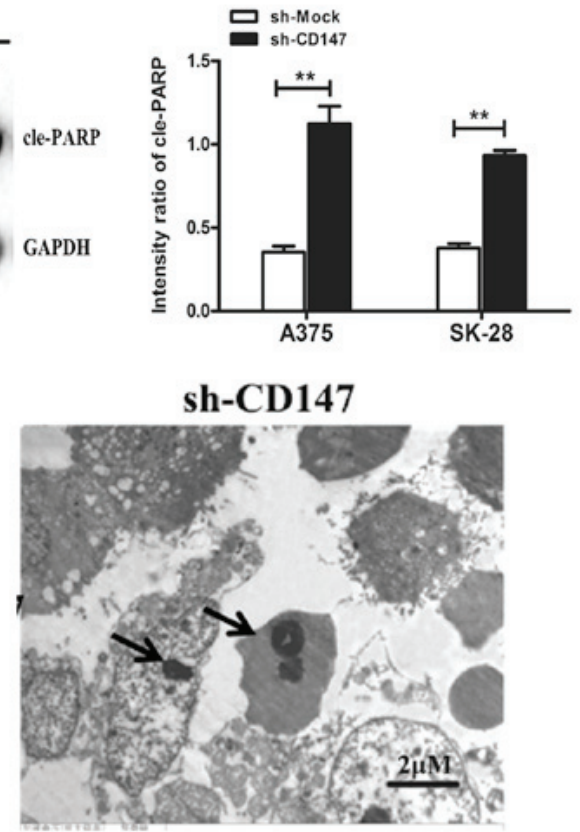

Figure 2. Inhibition of CD147 promotes the apoptosis of melanoma cell lines. (A) Representative dot plots of Annexin V-FITC and PI staining. After A375 cells were stably transfected with sh-Mock (left) or sh-CD147 vector (right), apoptosis analysis was performed by flow cytometry. (B) Apoptotic rate of sh-CD147- and sh-Mock-transfected A375 cells. The percentage of apoptotic cells was significantly higher with decreased CD147 expression. (C and D) Protein expression levels of apoptosis-associated cle-PARP in sh-CD147- and sh-Mock-transfected A375 and SK-28 cells. (E) Transmission electron microscopy images of apoptosis of sh-CD147-transfected and sh-Mock-transfected A375 cells. Apoptotic bodies are indicated by arrows. $\mathrm{n}=3$ for each experiment. Scale bar $=2 \mu \mathrm{m}$. ${ }^{* *} \mathrm{P}<0.01$. CD147, cluster of differentiation 147; cle-PARP, cleaved poly (ADP-ribose) polymerase; FITC, fluorescein isothiocyanate; PI, propidium iodide; sh, short hairpin RNA.

High-throughput screening to determine the apoptosisrelated proteins associated with CD147 in melanoma cells. In the present study, the total apoptosis-associated proteins in A375-sh-Mock- and A375-sh-CD147-transfected cells were investigated via a human apoptosis antibody array. Then, 43 apoptosis-associated proteins in the array were detected by comparing the fluorescence spectra and the corresponding fluorescence values (Fig. 3A). Finally, 9 apoptosis-associated proteins were selected, which exhibited significantly different expression compared with the control group. Among these proteins, CD40 ligand (CD40L), p53, cellular inhibitor of apoptosis 2 (cIAP-2), Survivin, tumor necrosis factor (TNF)related apoptosis-inducing ligand 2 (TRAILR-2) and p21 were $>1.5$-fold higher in A375-sh-CD147 cells, and three proteins, including heat shock protein 60 (Hsp60), IGFBP-6 and IGFBP-2, had decreased by 0.178 - to 0.606 -fold (Table I). As IGFBP2 expression exhibited the most significant change (0.178-fold) by statistical analysis, IGFBP2 was selected for the subsequent analysis.

Consistent with the results from the human apoptosis assay, IGFBP 2 mRNA by qPCR assay and protein expression was significantly reduced in A375-sh-CD147 cells compared
Table I. Differential expression of apoptosis-associated proteins in A375-sh-CD147 cells compared to A375-sh-Mock control cells.

\begin{tabular}{lrrr}
\hline & \multicolumn{2}{c}{ Average intensity } & \\
\cline { 2 - 3 } Gene & \multicolumn{1}{c}{ Control } & sh-CD147 & Ratio \\
\hline CD40L & 280.75 & 572.75 & 2.040 \\
p53 & $2,457.00$ & $4,910.00$ & 1.998 \\
cIAP-2 & 137.75 & 269.00 & 1.953 \\
Survivin & $5,983.50$ & $10,351.75$ & 1.730 \\
TRAILR-2 & 138.75 & 218.25 & 1.573 \\
p21 & $37,326.00$ & $56,199.00$ & 1.506 \\
Hsp60 & $3,183.75$ & $1,930.50$ & 0.606 \\
IGFBP6 & 855.75 & 450.50 & 0.526 \\
IGFBP2 & $1,425.25$ & 254.25 & $0.178^{\mathrm{a}}$ \\
\end{tabular}

${ }^{\mathrm{a}} \mathrm{P}<0.05$ vs. control. CD40L, cluster of differentiation 40 ligand; cIAP-2, cellular inhibitor of apoptosis 2; Hsp, heat shock protein; IGFBP, insulinlike growth factor-binding protein; sh, short hairpin RNA; TRAILR, tumor necrosis factor-related apoptosis-inducing ligand receptor. 
A

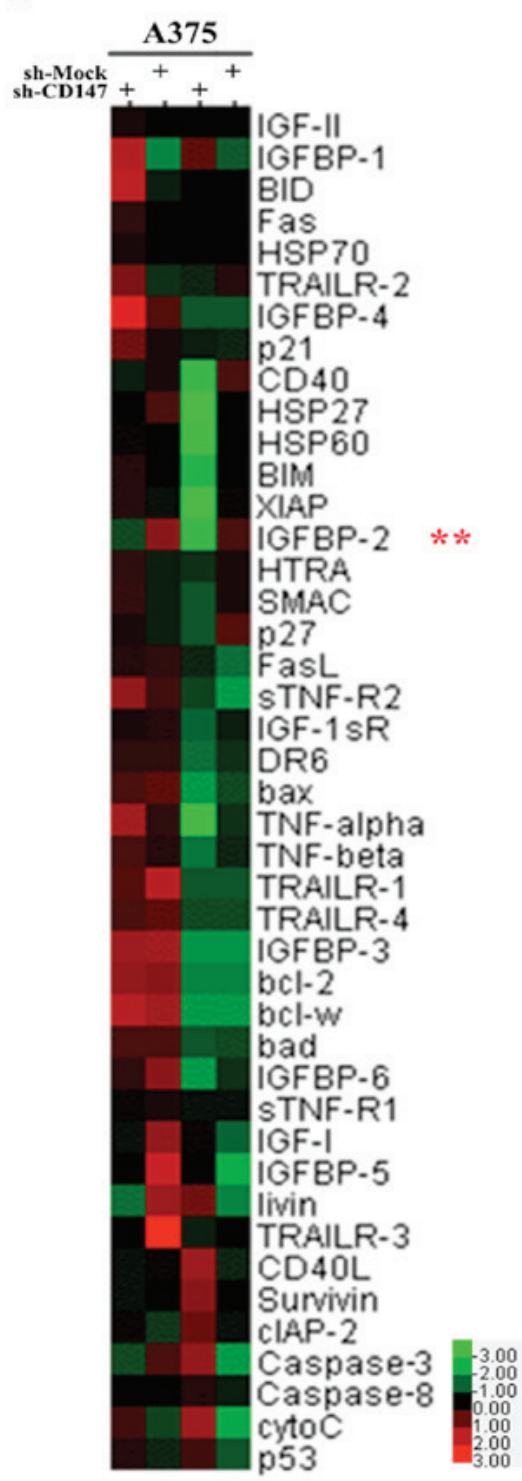

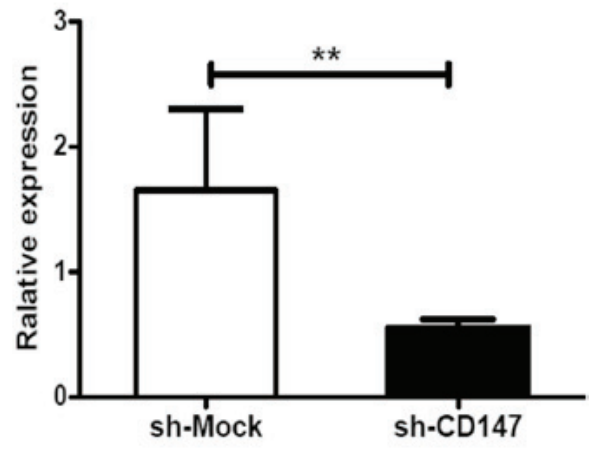

C

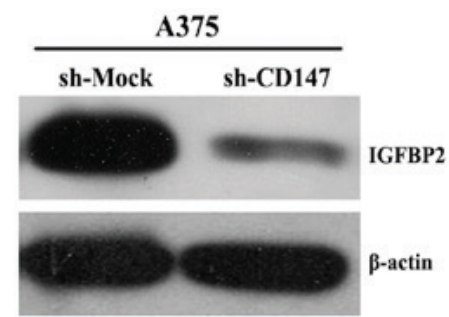

SK-28

sh-Mock sh-CD147

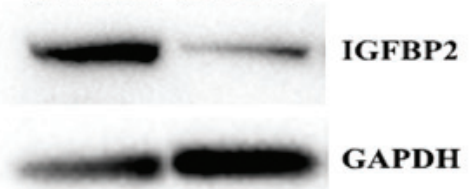

D

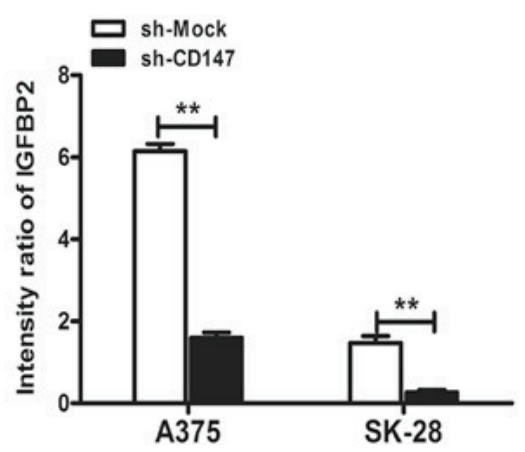

Figure 3. IGFBP2 is an apoptosis-associated protein in sh-CD147 melanoma cells. (A) Cluster analysis of the expression of 43 apoptosis-associated proteins in sh-CD147- and sh-Mock-transfected A375 cells. Green presented downregulation and red indicated higher protein expression relative to the mean expression of all samples. (B) Relative mRNA expression of IGFBP2 in sh-Mock- and sh-CD147-transfected A375 cells. (C and D) Quantitation of the protein expression levels of IGFBP2 in sh-Mock- and sh-CD147-transfected A375 and SK-28 cells was performed via western blotting using ImageJ software. $n=3$ for each experiment. " ${ }^{* *}<0.01$ vs. sh-Mock. Bcl-2, B-cell lymphoma 2; Bcl-w, Bcl-2-like protein 2; Bad, Bcl-2-associated agonist of cell death; BID, BH3 interactingdomain death agonist; BIM, Bcl-2-like protein 11; CD147, cluster of differentiation 147; CD40L, CD40 ligand; cIAP-2, cellular inhibitor of apoptosis 2; cytoC, cytochrome $c$; FasL, Fas ligand; HSP, heat shock protein; HTRA, HtrA serine peptidase; IGFBP2, insulin-like growth factor-binding protein 2; sh, short hairpin RNA; SMAC, second mitochondria-derived activator of caspases; TNF, tumor necrosis factor; sTNF-R2, soluble TNF receptor 2; TRAILR, TNFrelated apoptosis-inducing ligand receptor; XIAP, X-linked inhibitor of apoptosis protein.

with sh-Mock cells (Fig. 3B-D). In addition, downregulation of IGFBP2 expression induced by sh-CD147 was investigated in SK28-sh-CD147 melanoma cells (Fig. 3C and D). Collectively, the findings demonstrated that CD147 was positively associated with IGFBP2 in melanoma cells.

CD147 regulates IGFBP2 expression via the PTEN/PI3K/AKT signaling pathway. To investigate the regulatory mechanism associated with CD147 and IGFBP2, whether CD147 interacted with IGFBP2 in melanoma cells was determined; however, no interaction between CD147. Providing that IGFBP2 is a downstream molecule in the PTEN/PI3K/AKT signaling pathway, the AKT-mTOR signaling pathway was investigated. The results demonstrated that p-AKT and p-mTOR expression was significantly decreased when CD147 expression was downregulated in A375 and SK-28 cells compared with in sh-Mock-transfected cells (Fig. 4A-C); however, the expression of the phosphatase PTEN was significantly increased in A375-sh-CD147 and SK-MEL-28-sh-CD147 cells compared with in sh-Mock-transfected cells (Fig. 4D). Importantly, it 
A

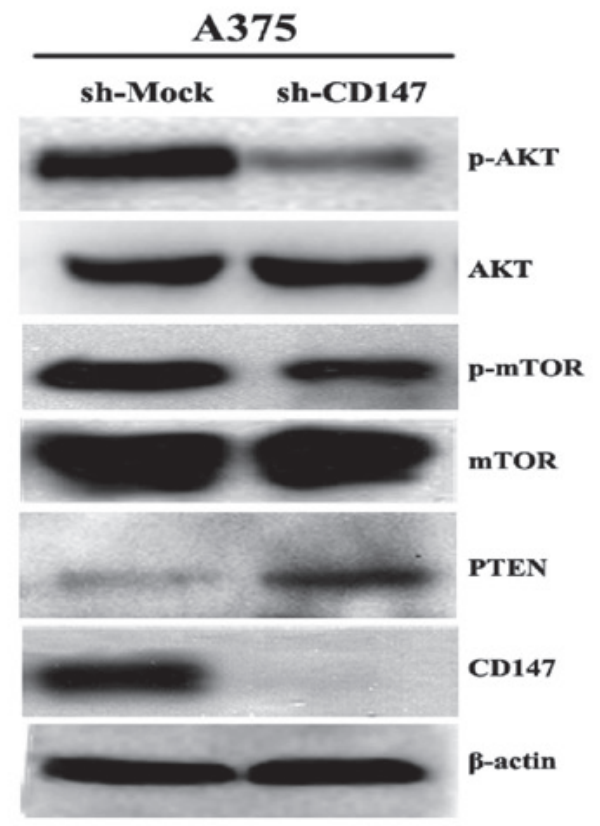

B

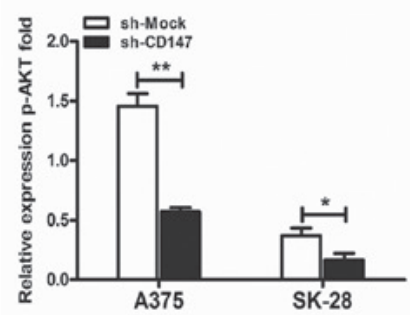

E

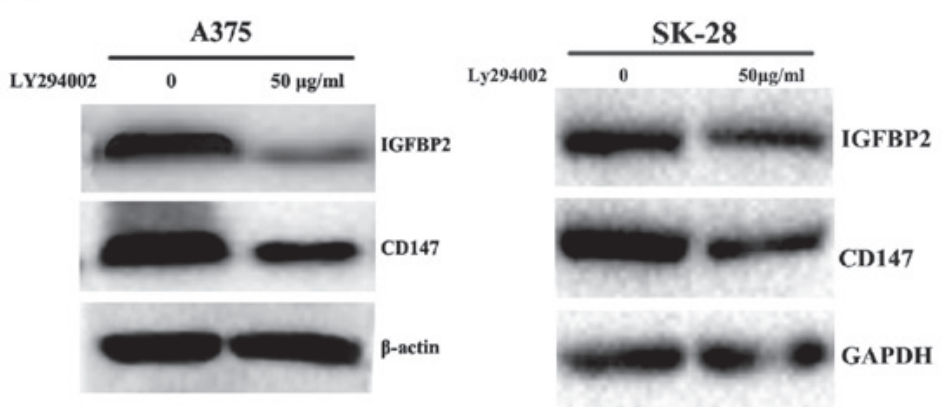

SK-28

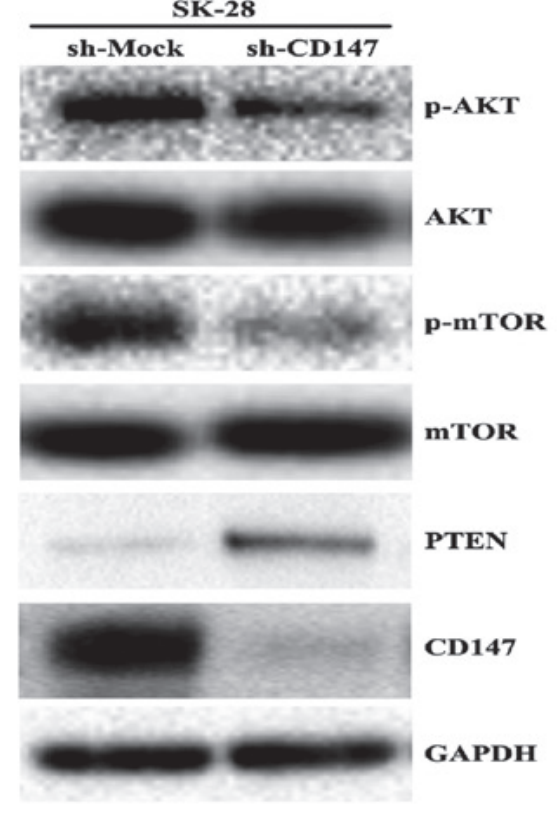

D

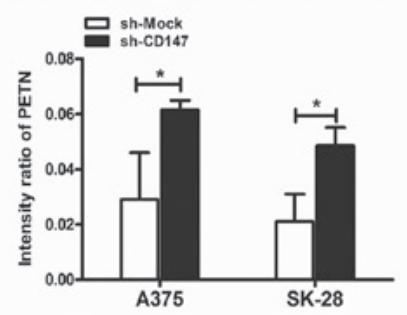

$\mathbf{F}$

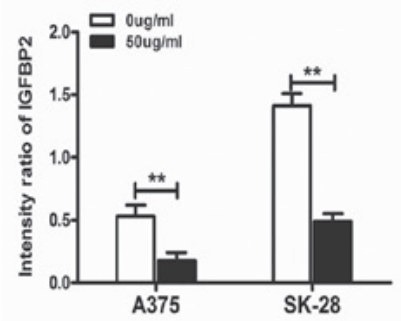

Figure 4. CD147 regulates IGFBP2 expression via the PTEN/PI3K/AKT signaling pathway. (A) Cell lysates of sh-CD147 and sh-Mock A375 and SK-MEL-28 cells were subjected to western blotting to detect p-AKT, p-mTOR and PTEN expression. Quantitation of (B) p-AKT, (C) p-mTOR and (D) PTEN expression

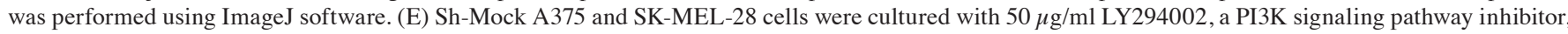
for $24 \mathrm{~h}$. IGFBP2 and CD147 expression was detected by western blotting and (F) quantitative analysis of IGFBP2 expression was performed using ImageJ software. $\mathrm{n}=3$ for each experiment. ${ }^{*} \mathrm{P}<0.05,{ }^{* *} \mathrm{P}<0.01$ vs. sh-Mock or $0 \mu \mathrm{g} / \mathrm{ml} \mathrm{LY} 294002$. AKT, protein kinase B; CD147, cluster of differentiation 147; m-TOR; p, phosphorylated; PI3K, phosphoinositide 3-kinase; PTEN, phosphatase and tensin homolog; sh, short hairpin RNA.

was observed that LY294002, a direct inhibitor of the PI3K signaling pathway, significantly decreased IGFBP2 protein expression in sh-Mock A375 and sh-Mock SK-MEL-28 cells compared with the untreated groups (Fig. 4E and F). The results of the present study indicated that CD147 upregulated the expression of IGFBP2 by activating the PTEN/PI3K/AKT signaling pathway in melanoma cells.

In vivo experiments show that CD147 combined with IGFBP2 mediates apoptosis in melanoma. In the present study, a xenograft mouse model was successfully generated by inoculating melanoma A375-sh-CD147 and A375-sh-Mock cells into mice. As expected, after 35 days following inoculation of the melanoma cells, it was observed that the average tumor volume in the A375-sh-CD147 group was notably lower compared with that in the sh-Mock group (Fig. 5A). The pathological characteristics of malignant melanoma were confirmed via HE staining (Fig. 5B).

In addition, it was reported that the expression levels of CD147 and IGFBP2 in the A375-sh-CD147-inoculated group 
A

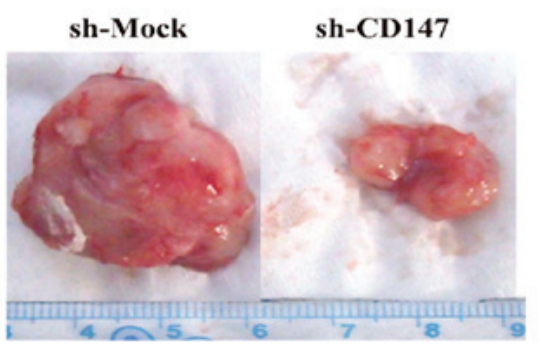

B

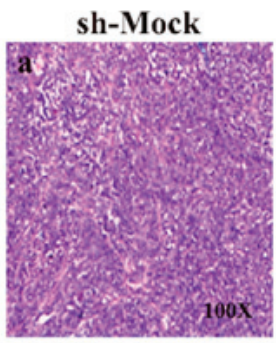

sh-CD147

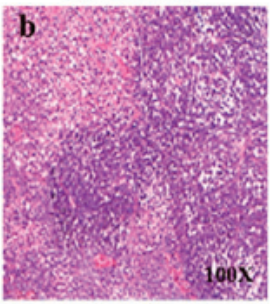

C
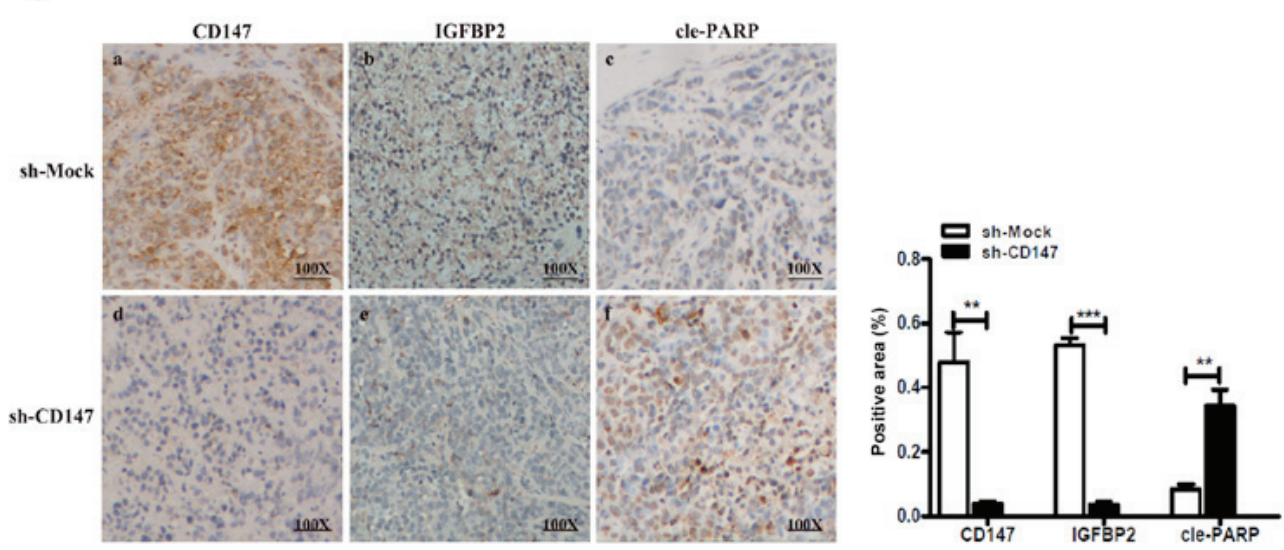

D
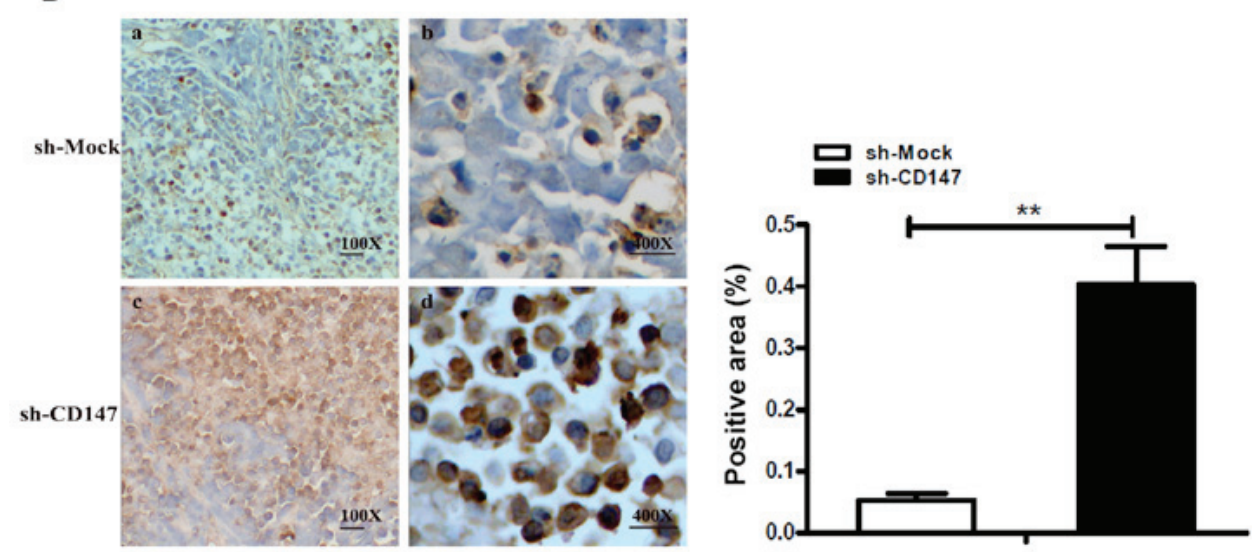

Figure 5. CD147 with IGFBP2 mediates the apoptosis of melanoma cells in vivo. (A) Tumor volume in the xenograft mouse model generated by inoculating melanoma sh-CD147 A375 and sh-Mock A375 cells. ${ }^{* *} \mathrm{P}<0.05$ or ${ }^{* * * *} \mathrm{P}<0.01$ vs. sh-Mock. (B) Pathological characteristics of xenograft mouse tumors were observed by HE staining. Magnification, x100. (C) Representative immunohistochemical staining for CD147, IGFBP2 or cle-PARP in serial sections of sh-CD147-injected xenograft mouse tumors or sh-Mock tumors. Magnification, x100. The area positive for CD147, IGFBP2 and cleaved PARP- in sh-CD147 or sh-Mock cell-injected xenograft mouse tumors was determined by using Image-Pro Plus 6.0 software. (D) Representative TUNEL assay in sh-CD147-injected xenograft mouse tumors and sh-Mock tumors; the apoptosis-positive regions are indicated in brown-yellow. The histogram indicated the TUNEL-positive area (\%) (right). Magnifications, x100 or x400. CD147, cluster of differentiation 147; cle-PARP, cleaved poly (ADP-ribose) polymerase; IGFBP2, insulin-like growth factor-binding protein 2; sh, short hairpin RNA; TUNEL, terminal deoxynucleotidyl-transferase-mediated dUTP nick end labeling.

were significantly decreased compared with the control group; CD147 was mainly expressed in the cell membranes in tumor tissue, while IGFBP2 was mainly located in the cytoplasm (Fig. 5C). The expression levels of the apoptosis-associated protein, cle-PARP, were significantly increased compared with the control group. Therefore, it was suggested that CD147 could upregulate the expression of IGFBP2 in vivo, and CD147 induced melanoma cell apoptosis via the regulation of IGFBP2 expression.

Additionally, the apoptotic area in tumor tissues from the xenograft mouse model was determined from a TUNEL assay as Fig. 5D. The results revealed that the positive expression rate was significantly higher in the A375-sh-CD147 cell group compared with the control. The results of the present study indicated that the expression levels of IGFBP2 and CD147 were positively associated in vivo, and the inhibition of CD147 may induce the apoptosis of MM cells via the regulation of IGFBP2 expression.

CD147 and IGFBP2 overexpression in melanoma tissues. To further investigate the association between CD147 and IGFBP2, the expression of CD147 and IGFBP2 in 15 paraffin-embedded specimens with a clinical diagnosis of nevus was determined; the results revealed low expression levels of CD147 and 
A

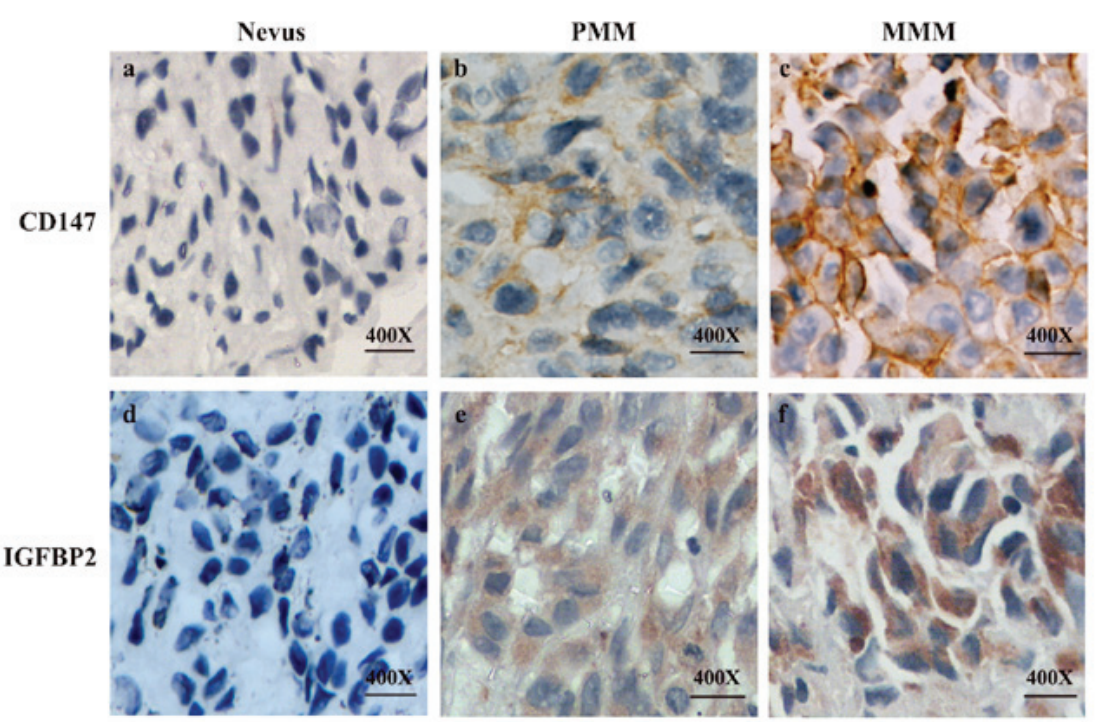

B

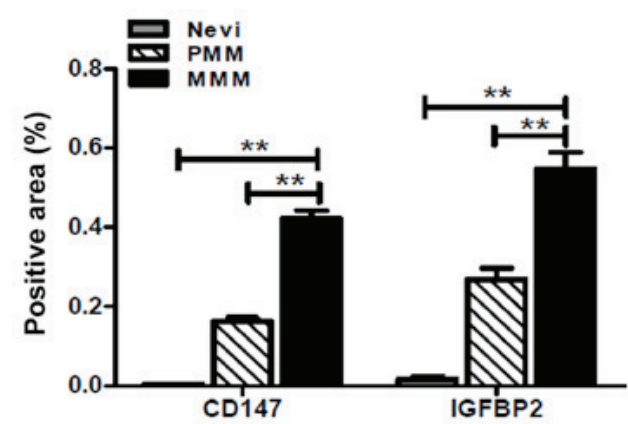

Figure 6. CD147 and IGFBP2 overexpression in melanoma tissues. (A) Representative immunohistochemical staining of CD147- or IGFBP2-positive cells in nevus ( $\mathrm{n}=15)$, PMM ( $\mathrm{n}=128)$ and MMM ( $\mathrm{n}=64)$ tissues. Magnification, $\mathrm{x} 100$. (B) Comparison of the CD147- and IGFBP2-positive area (\%) in nevus and melanoma microassay tissue. Semi-quantitation was performed using Image-Pro Plus 6.0 software. ${ }^{* *} \mathrm{P}<0.05 \mathrm{MMM}$ vs. PMM or nevus. MMM, metastatic malignant melanoma; PMM, primary malignant melanoma.

Table II. Relative expression of CD147 and IGFBP2 in PMM and MMM.

\section{A, CD147 expression}

Tumor type Cases Weak Moderate Strong Positive rate (\%)

\begin{tabular}{lrcccl}
\hline PMM & 128 & 28 & 68 & 32 & 78.1 \\
MMM & 64 & 4 & 11 & 49 & $93.8^{\mathrm{a}}$ \\
\hline
\end{tabular}

\section{B, IGFBP2 expression}

Tumor type Cases Weak Moderate Strong Positive rate (\%)

\begin{tabular}{lrrrrl}
\hline PMM & 128 & 25 & 75 & 28 & 80.5 \\
MMM & 64 & 6 & 18 & 40 & $90.6^{\mathrm{a}}$
\end{tabular}

${ }^{\mathrm{a}} \mathrm{P}<0.05$ vs. PMM. CD, cluster of differentiation; IGFBP2, insulinlike growth factor-binding protein 2; PMM, primary malignant melanoma; MMM, metastatic malignant melanoma.

IGFBP2 (Fig. 6A). In addition, an MM tissue microarray was employed, which contained 128 cases of primary MM (PMM) and 64 cases of metastatic MM (MMM). The expression of CD147 and IGFBP2 in two adjacent microarray tissues were observed; the expression of CD147 and IGFBP2 was higher compared with in the nevus tissue (Fig. 6A and B). The semiquantitation results revealed that area of positive expression of CD147 in PMM and MMM were 78.1 and 93.8\% respectively, which was significantly higher than that of the nevus tissue (Table II). Similar findings were observed with IGFBP2 expression in MM; the area of positive expression of IGFBP2 were 80.5 and 90.6\% in PMM and metastatic MM, respectively, which was significantly higher than the nevus tissue (Table II). Importantly, the expression levels of CD147 and IGFBP2 were positively associated in human MM (Table II).

Collectively, these findings indicate that CD147 regulated the expression of IGFBP2 in MM, and may participate in tumor occurrence and development. Therefore, the CD147/IGFBP2 axis may serve an important role in the transformation process of pigmented moles to MM.

\section{Discussion}

CD147 serves a key role in facilitating tumor cell invasiveness and metastasis by regulating matrix metalloproteinase (MMP) expression, including MMP-1, MMP-2, MMP-9 and A membrane-type 1-MMP, in adjacent fibroblasts or cancer 
cells $(18,20)$. For example, in hepatocellular carcinoma (HCC), CD147 is highly upregulated and inhibition of CD147 significantly inhibited HCC cell proliferation and metastasis via MMP production (21). In addition, it has been demonstrated that CD147 is upregulated in various multidrug-resistant cancer cells, including breast cancer, HCC and ovarian cancer cells (22). Suppression of CD147 increased the sensitivity of SKOV3 and OVCAR3 ovarian cells to paclitaxel treatment (23). In spermatogenesis, knockdown of CD147 promoted apoptosis in spermatocytes in a p53-independent manner (24). Recently, novel evidence has demonstrated that suppressing CD147 inhibited TNF receptor-associated factor 2 expression, leading to alterations in canonical and non-canonical nuclear factor- $\kappa \mathrm{B}$ activity, which may increase apoptosis in spermatocytes (25). CD147 has been demonstrated to induce endoplasmic reticulum stress to attenuate apoptosis and increase chemoresistance by increasing the transcriptional levels of binding immunoglobulin protein in HCC (26).

In the present study, it was reported that knockdown of CD147 significantly increased melanoma cell apoptosis. Using a xenograft mouse model, it was observed that knockdown of CD147 attenuated tumor cell growth via the induction of cellular apoptosis in vivo, suggesting that CD147 may serve an important role in melanoma apoptosis in vitro and in vivo. Importantly, via the human apoptosis array, we identified that the expression of 9 apoptosis-associated proteins, including CD40L, Hsp60, IGFBP2, IGFBP6, Survivin, TRAILR-2, cIAP-2, p21 and p53, was markedly altered following the suppression of CD147 expression. Furthermore, the present study reported the downregulation of IGFBP2 expression following CD147 knockdown.

The IGF axis is crucial for biological functions, including cell growth and apoptosis. The IGF-induced signaling pathway constitutes several components, including the two ligands (IGF-I and IGF-II), corresponding receptors (IGF-1 and -2R) and IGFBPs, which serve key roles in modulating the activity of the IGF signaling pathway (27). IGFBP2 may associate with IGF to form a complex, which can readily translocate via the endothelial barrier, and reach local tissues to interact with integrin and elements of the extracellular matrix (28). Therefore, IGFBP2 acts as a container that harbors IGF in the local tissues (29). IGFBP2 has been reported to be overexpressed in tumors, including glioma, prostate, breast and lung cancers (30). It was reported that ectopic expression of IGFBP2 attenuated camptothecin-induced apoptosis, while inhibition of IGFBP2 increased sensitivity to camptothecin-induced death of NCI-H522 cells (31). Chen et al (24) demonstrated that IGFBP2 is highly expressed in lung cancer cells compared with in normal epithelial tissues, and intracellular IGFBP2 inhibited apoptosis via the regulation of caspase-3 activation.

The PI3K signaling pathway-specific inhibitor LY294002 decreased IGFBP2 expression in the present study. Furthermore, p-AKT, p-mTOR and IGFBP2 expression levels were significantly decreased, whereas PTEN expression was significantly increased in CD147-knockdown melanoma cells. The findings of the present study revealed that the PTEN/PI3K/AKT signaling pathway may be associated with IGFBP2 expression in melanoma cells. PTEN is able to catalyze the dephosphorylation of PIP3, which is a key secondary messenger for downstream signaling pathway activation. Providing the frequent loss or inactivation of PTEN function in tumors, accumulating PIP3 may recruit proteins with pleckstrin homology domains to the cell membrane, including phosphoinositide-dependent kinase-1 and AKT (32). Consequently, PDK1 could directly phosphorylate and activate AKT $(33,34)$; activated AKT isoforms (AKT1, AKT2 and AKT3) may induce a variety of malignant phenotypes, including cell proliferation, cell death, angiogenesis and cellular metabolism by activating downstream molecules, including glycogen synthase kinase 3 , forkhead box $\mathrm{O}$, B-cell lymphoma 2 (Bcl-2)-associated antagonist of cell death, mouse double minute 2 homolog and p27 (35-37). Importantly, AKT also activates the mTOR complex 1 (mTORC1) via the phosphorylation and inhibition of proline-rich AKT substrate 40, which is a negative regulator of mTORC1 $(38,39)$. Activation of following PTEN inactivation promotes the translation of specific mRNAs and the synthesis of proteins involved in cell proliferation (40). Based on the findings of the present study, it was hypothesized that inhibition of CD147 in melanoma cells could increase PTEN activation, and that the phosphatase activity of PTEN may decrease the intracellular p-AKT levels, promoting the apoptosis of melanoma cells.

Interestingly, evidence has demonstrated that IGFBP2 is the most significantly altered molecule following PTEN loss and PI3K/AKT activation. The expression of IGFBP2 was observed to be upregulated in $\mathrm{PTEN}^{-/}$cancers (41). Inhibition of PI3K/AKT activation by LY294002 was observed to significantly inhibit IGFBP2 expression, which suggests that the PTEN/PI3K/AKT signaling pathway may regulate IGFBP2 expression in prostate cancer and glioblastoma (42). In addition, inhibiting the activation of PI3K/AKT reduced the expression of IGFBP2 via the specificity protein-1 transcription factor in MCF-7 breast cancer cells (43). Consistent with these results, the present study also reported that the inhibition of PI3K/AKT by LY294002 attenuated IGFBP2 expression in melanoma cells. Therefore, the underlying mechanism of CD147-regulated expression of PTEN or PI3K/AKT activation requires further investigation to provide novel insight into the role of CD147 in melanoma.

Collectively, the results of the present study demonstrated that CD147 serves a key role in melanoma cell apoptosis, which may be mediated via IGFBP2 and the PTEN/PI3K/AKT signaling pathway. In addition, the expression of IGFBP2 and CD147 was upregulated and exhibited a positive association in melanoma clinical tissues, suggesting that CD147 may be a potential therapeutic target in chemotherapy or a target for the prevention of melanoma.

\section{Acknowledgements}

We are very grateful to Dr Minxue Shen who kindly gave us advice for data statistics.

\section{Funding}

This work was supported by grants from the National Natural Science Foundation of China (grant no. 81402263), China National Funds for Distinguished Young Scientists (grant no. 81225013), the Major International (Regional) Joint Research Program of China (grant no. 1620108024), the Special 
Foundation For State Major Basic Research Program of China (grant no. 81430075), the Strategy-Oriented Special Project of Central South University in China (grant no. ZLXD2017003); the National Natural Science Foundation of China (grant no. 81572679) and the National Natural Science Foundation of China (grant no. 81673046).

\section{Availability of data and materials}

All data generated or analyzed during this study are included in this published article.

\section{Authors' contributions}

SZ, LW and YK performed all of experiments the research and wrote the manuscript. JS, ZL, JL, JZ and FL analyzed and interpreted the patient data. YW, WC, YH, JT, JZ and XX critically revised the manuscript for important intellectual information. $\mathrm{CP}$ and $\mathrm{XC}$ made substantial contributions to the concenption and design of the present study. All authors read and approved the final manuscript.

\section{Ethics approval and consent to participate}

The present study was approved by the Ethics Committee of Xiangya Hospital, Central South University (Changsha, China). Informed consent was obtained from all patients.

\section{Patient consent for publication}

Not applicable.

\section{Competing interests}

The authors declare that they have no competing interests.

\section{References}

1. Zimmer L, Haydu LE, Menzies AM, Scolyer RA, Kefford RF, Thompson JF, Schadendorf D and Long GV: Incidence of new primary melanomas after diagnosis of stage III and IV melanoma. J Clin Oncol 32: 816-823, 2014.

2. Arnold M, Holterhues C, Hollestein LM, Coebergh JW, Nijsten T, Pukkala E, Holleczek B, Tryggvadóttir L, Comber H, Bento MJ, et al: Trends in incidence and predictions of cutaneous melanoma across Europe up to 2015. J Eur Acad Dermatol Venereol 28: $1170-1178,2014$.

3. Yin H, Shao Y and Chen X: The effects of CD147 on the cell proliferation, apoptosis, invasion, and angiogenesis in glioma. Neurol Sci 38: 129-136, 2017.

4. Kuang YH, Chen X, Su J, Wu LS, Liao LQ, Li D, Chen ZS and Kanekura T: RNA interference targeting the CD147 induces apoptosis of multi-drug resistant cancer cells related to XIAP depletion. Cancer Lett 276: 189-195, 2009.

5. Xie W, Xie H, Liu F, Li W, Dan J, Mei Y, Dan L, Xiao X, Li J and Chen X: Propranolol induces apoptosis of human umbilical vein endothelial cells through downregulation of CD147. Br J Dermatol 168: 739-748, 2013.

6. Zhao S, Kuang YH and Chen X: Overexpression of CD147 inhibits Chinese Hamster Ovary cells apoptosis due to inducing methotrexate efflux. J Dermatol 39: 170-170, 2012.

7. Yu JS and Cui W: Proliferation, survival and metabolism: The role of PI3K/AKT/mTOR signalling in pluripotency and cell fate determination. Development 143: 3050-3060, 2016.

8. Lian C, Guo Y, Zhang J, Chen X and Peng C: Targeting CD147 is a Novel Strategy for Antitumor Therapy. Curr Pharm Des 23: 4410-4421, 2017
9. Stocker H, Andjelkovic M, Oldham S, Laffargue M, Wymann MP, Hemmings BA and Hafen E: Living with lethal PIP3 levels: Viability of flies lacking PTEN restored by a PH domain mutation in Akt/PKB. Science 295: 2088-2091, 2002.

10. Abraham J: PI3K/AKT/mTOR pathway inhibitors: The ideal combination partners for breast cancer therapies? Expert Rev Anticancer Ther 15: 51-68, 2015.

11. Bucheit AD, Chen G, Siroy A, Tetzlaff M, Broaddus R, Milton D, Fox P, Bassett R, Hwu P, Gershenwald JE, et al: Complete loss of PTEN protein expression correlates with shorter time to brain metastasis and survival in stage IIIB/C melanoma patients with BRAFV600 mutations. Clin Cancer Res 20: 5527-5536, 2014.

12. Dong Y, Richards JA, Gupta R, Aung PP, Emley A, Kluger Y, Dogra SK, Mahalingam M and Wajapeyee N: PTEN functions as a melanoma tumor suppressor by promoting host immune response. Oncogene 33: 4632-4642, 2014.

13. Zhang W and Fuller G: IGFBP2 as a brain tumor oncogene. Cancer Biol Ther 6: 995-996, 2007.

14. Sztefko K, Hodorowicz-Zaniewska D, Popiela T and Richter P: IGF-I, IGF-II, IGFBP2, IGFBP3 and acid-labile subunit (ALS) in colorectal cancer patients before surgery and during one year follow up in relation to age. Adv Med Sci 54: 51-58, 2009.

15. Moore LM, Holmes KM, Smith SM, Wu Y, Tchougounova E, Uhrbom L, Sawaya R, Bruner JM, Fuller GN and Zhang W: IGFBP2 is a candidate biomarker for Ink4a-Arf status and a therapeutic target for high-grade gliomas. Proc Natl Acad Sci USA 106: 16675-16679, 2009.

16. Zeng W, Su J, Wu L, Yang D, Long T, Li D, Kuang Y, Li J, Qi M, Zhang J, et al: CD147 promotes melanoma progression through hypoxia-induced MMP2 activation. Curr Mol Med 14: 163-173, 2014.

17. Livak KJ and Schmittgen TD: Analysis of relative gene expression data using real-time quantitative PCR and the 2(-Delta Delta C(T)) Method. Methods 25: 402-408, 2001.

18. Chen X, Lin J, Kanekura T, Su J, Lin W, Xie H, Wu Y, Li J, Chen $\mathrm{M}$ and Chang J: A small interfering CD147-targeting RNA inhibited the proliferation, invasiveness, and metastatic activity of malignant melanoma. Cancer Res 66: 11323-11330, 2006.

19. Council NR: Guide for the Care and Use of Laboratory Animals. The National Academies Press, Washington, DC, 1996.

20. Su J, Gao T, Jiang M, Wu L, Zeng W, Zhao S, Peng C and Chen X: CD147 silencing inhibits tumor growth by suppressing glucose transport in melanoma. Oncotarget 7: 64778-64784, 2016.

21. Gou X, Tang X, Kong DK, , He X, Gao X, Guo N, Hu Z, Zhao Z and Chen Y: CD147 is increased in HCC cells under starvation and reduces cell death through upregulating p-mTOR in vitro. Apoptosis 21: 110-119, 2016.

22. Li QQ, Wang WJ, Xu JD, Cao XX, Chen Q, Yang JM and Xu ZD: Up-regulation of CD147 and matrix metalloproteinase-2, -9 induced by $\mathrm{P}$-glycoprotein substrates in multidrug resistant breast cancer cells. Cancer Sci 98: 1767-1774, 2007.

23. Zou W, Yang H, Hou X, Zhang W, Chen B and Xin X: Inhibition of CD147 gene expression via RNA interference reduces tumor cell invasion, tumorigenicity and increases chemosensitivity to paclitaxel in HO-8910pm cells. Cancer Lett 248: 211-218, 2007.

24. Chen H, Fok KL, Jiang X, Jiang J, Chen Z, Gui Y, Chan HC and Cai Z: CD147 regulates apoptosis in mouse spermatocytes but not spermatogonia. Hum Reprod 27: 1568-1576, 2012.

25. Wang C, Fok KL, Cai Z, Chen H and Chan HC: CD147 regulates extrinsic apoptosis in spermatocytes by modulating NFKB signaling pathways. Oncotarget 8: 3132-3143, 2017.

26. Tang J, Guo YS, Zhang Y, Yu XL, Li L, Huang W, Li Y, Chen B, Jiang JL and Chen ZN: CD147 induces UPR to inhibit apoptosis and chemosensitivity by increasing the transcription of Bip in hepatocellular carcinoma. Cell Death Differ 19: 1779-1790, 2012.

27. Reynolds CM, Perry JK and Vickers MH: Manipulation of the growth hormone-insulin-like growth factor (GH-IGF) axis: A treatment strategy to reverse the effects of early life developmental programming. Int J Mol Sci 18: 18, 2017.

28. Podlutsky A, Valcarcel-Ares MN, Yancey K, Podlutskaya V, Nagykaldi E, Gautam T, Miller RA, Sonntag WE, Csiszar A and Ungvari Z: The GH/IGF-1 axis in a critical period early in life determines cellular DNA repair capacity by altering transcriptional regulation of DNA repair-related genes: Implications for the developmental origins of cancer. Geroscience 39: 147-160, 2017.

29. Sehgal P, Kumar N, Praveen Kumar VR, Patil S, Bhattacharya A Vijaya Kumar M, Mukherjee G and Kondaiah P: Regulation of protumorigenic pathways by insulin like growth factor binding protein 2 and its association along with $\beta$-catenin in breast cancer lymph node metastasis. Mol Cancer 12: 63, 2013. 
30. Chua CY, Liu Y, Granberg KJ, Hu L, Haapasalo H, Annala MJ, Cogdell DE, Verploegen M, Moore LM, Fuller GN, et al: IGFBP2 potentiates nuclear EGFR-STAT3 signaling. Oncogene 35: 738-747, 2016

31. Biernacka KM, Uzoh CC, Zeng L, Persad RA, Bahl A, Gillatt D, Perks CM and Holly JM: Hyperglycaemia-induced chemoresistance of prostate cancer cells due to IGFBP2. Endocr Relat Cancer 20: 741-751, 2013.

32. $\mathrm{Wu} \mathrm{H}$, Goel V and Haluska FG: PTEN signaling pathways in melanoma. Oncogene 22: 3113-3122, 2003.

33. Shen X, Xi G, Radhakrishnan Y and Clemmons DR: PDK1 recruitment to the SHPS-1 signaling complex enhances insulinlike growth factor-i-stimulated AKT activation and vascular smooth muscle cell survival. J Biol Chem 285: 29416-29424, 2010.

34. Harris TK: PDK1 and PKB/Akt: Ideal targets for development of new strategies to structure-based drug design. IUBMB Life 55: 117-126, 2003.

35. Zhang Y, Wang SJ, Han ZH, Li YQ, Xue JH, Gao DF, Wu XS and Wang CX: PI3K/AKT signaling pathway plays a role in enhancement of eNOS activity by recombinant human angiotensin converting enzyme 2 in human umbilical vein endothelial cells. Int J Clin Exp Pathol 7: 8112-8117, 2014.

36. Li H, Zeng J and Shen K: PI3K/AKT/mTOR signaling pathway as a therapeutic target for ovarian cancer. Arch Gynecol Obstet 290: 1067-1078, 2014

37. Goschzik T, Gessi M, Denkhaus D and Pietsch T: PTEN mutations and activation of the PI3K/Akt/mTOR signaling pathway in papillary tumors of the pineal region. J Neuropathol Exp Neurol 73: 747-751, 2014.
38. Lv D, Liu J, Guo L, Wu D, Matsumoto K and Huang L: PRAS40 deregulates apoptosis in Ewing sarcoma family tumors by enhancing the insulin receptor/Akt and mTOR signaling pathways. Am J Cancer Res 6: 486-497, 2016.

39. Havel JJ, Li Z, Cheng D, Peng J and Fu H: Nuclear PRAS40 couples the Akt/mTORC1 signaling axis to the RPL11HDM2-p53 nucleolar stress response pathway. Oncogene 34: 1487-1498, 2015

40. Bhattacharya K, Maiti S and Mandal C: PTEN negatively regulates mTORC2 formation and signaling in grade IV glioma via Rictor hyperphosphorylation at Thr1135 and direct the mode of action of an mTORC1/2 inhibitor. Oncogenesis 5: e227, 2016.

41. Mehrian-Shai R, Chen CD, Shi T, Horvath S, Nelson SF, Reichardt JK and Sawyers CL: Insulin growth factor-binding protein 2 is a candidate biomarker for PTEN status and PI3K/ Akt pathway activation in glioblastoma and prostate cancer. Proc Natl Acad Sci USA 104: 5563-5568, 2007.

42. Ahani N, Karimi Arzenani M, Shirkoohi R, Rokouei M, Alipour Eskandani M and Nikravesh A: Expression of insulin-like growth factor binding protein-2 (IGFBP-2) gene in negative and positive human cytomegalovirus glioblastoma multiforme tissues. Med Oncol 31: 812, 2014.

43. Mireuta M,Darnel A and Pollak M: IGFBP-2 expression in MCF-7 cells is regulated by the PI3K/AKT/mTOR pathway through Sp1-inducedincrease in transcription. Growth Factors 28: 243-255, 2010.

This work is licensed under a Creative Commons Attribution-NonCommercial-NoDerivatives 4.0 International (CC BY-NC-ND 4.0) License. 